\title{
Comparación entre dieta hipograsa e hipocalórica, dieta mediterranea y dieta baja en hidratos de carbono sin restricción calórica ("cetogénica")
}

Comparison between low-fat-hypocaloric diet, mediterranean diet and low-carbohydrate normo-caloric diet ("ketogenic")

Shai I, y col. N Engl J Med, 2008 (359): 229-241

Objetivo

Comparar la pérdida de peso asociada a tres estrategias dietarias.

\section{Diseño, lugar y pacientes}

Ensayo clínico abierto, controlado y aleatorizado llevado a cabo en Dimona, Israel, entre 2005 y 2007. Fueron aleatorizados 322 sujetos moderadamente obesos -52 años de edad media, 31 de índice de masa corporal (IMC) promedio y $86 \%$ varonesa una de las siguientes tres dietas: hipograsa restringida en calorías ( $\downarrow \mathrm{Gr} \downarrow \mathrm{kcal})$; mediterránea restringida en calorías (MED $\downarrow$ kcal) o baja en hidratos de carbono sin restricción calórica o "cetogénica" ( $\downarrow \mathrm{HC})$.

\section{Intervención y medición de resultados principales} Los tres grupos fueron semejantes en sus características demográficas, peso, circunferencia abdominal (CA) y presión arterial (TA); la prevalencia de tabaquismo, diabetes, enfermedad coronaria, sus valores de laboratorio y en el uso de medicación. Cada grupo fue asignado a un nutricionista y fue dividido en seis subgrupos de 17 a 19 participantes, coordinando cada profesional sus seis subgrupos. Otro dietista realizó llamadas telefónicas de motivación a quienes presentaban dificultades de adherencia. Se evaluó el cambio de peso a los 24 meses, con análisis por intención de tratar.

\section{Resultados principales}

La pérdida de peso fue máxima entre el primero y el sexto mes, con una fase de mantenimiento de siete a 24 meses. Todos los grupos perdieron peso, pero las reducciones fueron mayores en $\downarrow$ HC y MED $\downarrow$ kcal que en $\downarrow$ Gr $\downarrow$ kcal. Ver tabla 1 .
Tabla 1: diferencias de resultados entre los grupos asignados a dieta hipograsa e hipocalórica, dieta mediterranea y dieta baja en hidratos de carbono sin restricción calórica o cetogénica.

\begin{tabular}{|c|c|c|c|c|c|}
\hline & $\mid$ |Gr| keal $(n=104)$ & MED|keal ( $n=109$ ) & HC] $(n=109)$ & p \\
\hline \multicolumn{2}{|c|}{ Adherencia a los 24 meses } & $90,4 \%$ & $85,3 \%$ & $78 \%$ & 0,04 \\
\hline \multirow{5}{*}{$\begin{array}{l}\text { Magnitud } \\
\text { promedio } \\
\text { del } \\
\text { cambio }\end{array}$} & Peso $(\mathrm{kg})$ & $-2,90$ & $-4,40$ & $-4,70$ & NS \\
\hline & IMC $\left(\mathrm{kg} / \mathrm{m}^{2}\right)$ & $-1,00$ & $-1,50$ & $-1,50$ & NS \\
\hline & HDL (mg/dL) & 6,40 & 8,40 & 6,30 & NS \\
\hline & LDL (mg/dL) & $-0,05$ & $-3,00$ & $-5,60$ & NS \\
\hline & Triglic ridos $(\mathrm{mg} / \mathrm{dL}$ & $-2,80$ & $-23,70$ & $-21,80$ & NS \\
\hline
\end{tabular}

$\downarrow$ Gr $\downarrow$ kcal: dieta hipograsa e hipocalórica. MED $\downarrow$ kcal: dieta "mediterránea" hipocalórica. $\downarrow$ HC: dieta baja en hidratos de carbono sin restricción calórica o "cetogénica". IMC: índice de masa corporal. NS: no significativo.

Todos los grupos presentaron descensos semejantes en la CA y la TA. El nivel de PCR disminuyó significativamente $(p<0,05)$ sólo en MED $\downarrow$ kcal y $\downarrow$ HC y la insulinemia, en todos los pacientes de los tres grupos. Entre los diabéticos, la proporción de $\mathrm{HbA} 1 \mathrm{c}$ a los 24 meses disminuyó $1,3 \%$ en $\downarrow$ Gr $\downarrow$ kcal, 1,1 en MED $\downarrow$ kcal y $0,8 \%$ en $\downarrow \mathrm{HC}$; con cambios significativos solo en este ultimo grupo $(p=0,45)$.

\section{Conclusiones}

Una dieta $\downarrow$ HC y MED $\downarrow$ kcal pueden ser alternativas más eficaces que una $\downarrow$ Gr $\downarrow$ kcal para obtener un descenso de peso. Se podrían respetar las preferencias personales en la elección de la alternativa nutricional.

Palabras clave: dieta, dieta mediterránea, grasas, carbohidratos, peso. Key words: diet, mediterranean diet, carbohydrate, weight. Fuente de financiamiento: no reportados.

\section{Comentario}

Tal como se había propuesto en investigaciones previas de menor duración $n^{1,2,3}$ este estudio muestra que las dietas MED $\downarrow$ kcal y $\downarrow$ HC son alternativas efectivas a la clásica $\downarrow$ Gr $\downarrow$ kcal. Sin embargo presenta algunos puntos a discutir: 1) no se informó a qué grupo pertenecían los 20 pacientes que iniciaron tratamiento antihipertensivo durante el estudio -la dieta cetogénica suele acompañarse de alimentos con mayor contenido de sodio- ni que alimentos se recomendaron en ésta para disminuir el aporte de grasas saturadas; 2) las diferencias en la pérdida de peso y en los cambios metabólicos atribuibles a la dieta mediterránea y cetogénica no fueron estadísticamente significativas, y no se especificaron los perfiles lipídicos de los participantes; 3 ) las mujeres estuvieron representadas solo en un $14 \%$ de la muestra; 4) se realizó un exhaustivo monitoreo del paciente y un gran detalle en la preparación de sus menúes, lo que vuelve incierta la factibilidad del mantenimien- to de este tipo de plan una vez concluido el contexto "experimental y controlado" de la investigación. Además, sería valioso tener información sobre el detalle contabilizado del valor calórico de la dieta cetogénica para poder evaluar la influencia de la distribución de los macronutrientes y su valor calórico total en los resultados obtenidos.

\section{Conclusiones de los comentadores}

Dado que las guías de prevención y tratamiento de la enfermedad cardiovascular recomiendan "cambios en el estilo de vida" con modificaciones en los esquemas nutricionales como paso previo al tratamiento farmacológico; celebramos la aparición de estudios de buen nivel metodológico que evalúen rigurosamente dichos "cambios en el estilo de vida".

Ricardo Sarandría y Agustina Liaudat [ Policlínico Modelo de Cipolletti. ricardo.sarandria@gmail.com ]

Sarandría R. Comparación entre dieta hipograsa e hipocalórica, dieta mediterranea y dieta baja en hidratos de carbno sin restricción calórica. Evid. actual. práct. ambul; 11(5): 135, Sep-oct.2008. Comentado de: Shai I y col. for the Dietary Intervention Randomized Controlled Trial (DIRECT) Group. Weight Loss with a Low-Carbohydrate, Mediterranean, or Low-Fat Diet. N Engl J Med, 2008 (359): 229-241. PMID: 15148064. Disponible em URL: http://www.annals.org/cgi/content/full/140/10/778 (último acceso 15/09/08).

\section{Referencia}

1. Gardner $\mathrm{C}$ y col. Comparison of the Atkins, Zone, Ornish, and LEARN diets for change in weight and related risk factors among overweight premenopausal women: the A TO Z Weight Loss Study: a randomized trial. JAMA 2007;297:969-977. [Erratum, JAMA 2007;298:178.]

2. Foster $\mathrm{G}$ y col. A randomized trial of a low-carbohydrate diet for obesity. N Engl J Med 2003;348:2082-2090

3. Nordmann A y col. Effects of low-carbohydrate vs low-fat diets on weight loss and cardiovascular risk factors: a meta-analysis of randomized controlled trials. Arch Intern Med 2006;166:285-293. [Erratum, Arch Intern Med 2006;166:932.] 